Proceedings of the Second Annual Forestry Symposium 1996: Management and Sustainable Utilization of Forest Resources, Sri Lanka, 6-7 December 1996. (Eds. Amarasekera, HS, Ranasinghe, D M SHK and Finlayson, $W$. Published by Department of Forestry and Environmental Science, University of Sri Jayewardenepura, Sri Lanka (1998)

\title{
WETTING CHARACTERISTICS OF SOME TROPICAL TREE SPECIES
}

\author{
M.B.D.P. Gunawardena', E.R.N. Gunawardena' and I.R. Calder ${ }^{2}$ \\ 'Department of Agricultural Engineering, University of Peradeniya \\ ${ }^{2}$ Institute of Hydrology, Wallingford, UK
}

\begin{abstract}
Interception is a physical process, which represents a definite loss of rain-water, since most plants can absorb water only through their roots. The quantity lost depends on how the canopy is wetted by the falling rain, and the amount of water stored on the vegetation after the rain stops. Information on these points is needed in modelling studies aimed at estimating the interception loss under varying climatic conditions. This study compared the wetting characterisitics of Acacia decurren, Artocarpus heterophyllus, Eucalyptus microcorys, Hedyotis confertiflora, Pinus caribaea, Rhododendron zeylanicum, Syzygium rotundifolium, and Tectona grandis. A rainfall simulator was used to generate three drop sizes. Maximum interception and interception loss for each species and for each drop size were measured on a branch representing a projected canopy area of one square metre. The results showed that the interception loss depends on the species and not on the raindrop size and that it is inversely proportional to leaf size. From the point of view of maximizing the catchment water vield, the species with larger leaves, such as jak and teak, which give the least interception losses, are more suitable for planting in drier areas, while species with smaller leaves are more suitable for wetter areas.
\end{abstract}

\section{Introduction}

Interception is the process whereby precipitation is caught by vegetation and is evaporated back into the atmosphere without ever reaching the ground. It represents a loss of rainfall, since most plants can absorb water only through their roots. Assuming that the evaporative demand is constant, the canopies that intercept the most rainfall are those that wet quickly, store more water, and allow smaller quantities to fall to the ground from the canopy storage after the cessation of the rainfall event. The actual wetting pattern in any given case depends on characteristics of the vegetation, such as the age and morphology of the plants, and also on climatic factors such as the duration and amount of rainfall and evaporation.

The estimation of maximum storage capacity (the maximum amount of water that the canopy can hold during the storm), and the canopy storage (the amount of water that the canopy retains after the cessation of rainfall) of a given vegetation and the effect of drop size on them is important in modelling interception loss from various landuse types (Calder, 1995). The interception loss from a Kandyan Forest Garden was predicted using a stochastic model which take these parameters in to account (Hall et al, 1995). Thercfore, it is important to 152 
study the wetting characteristics of different species, in order to assess the interception loss, so that the given physiographic and climatic region, suitable species can be selected to minimize the negative impact of the trees on the water yield from the catchment. This study was conducted to determined the wetting characteristics of some selected species, and to find the relationship of the interception loss with the drop size and the leaf area.

\section{Location, materials and method}

The study was carried out at Horton Plains, $20 \mathrm{~km}$ south of Nuwara Eliya, on the eastern edge of the we zone; this zone supports $8 \%$ (3160 ha) of Sri Lanka's remaining natural montane forest. Tributaries of the country's most important rivers, such as the Mahaveli, Kelani and Walawe, originate from these uplands. The land use comprises montane forest and grassland.

Eight species were selected: Hedyotis confertiflora, Rhododendron zeylanicum, Syzygium rotundifolium, Eucalyptus microcorws, Pinus caribaea ("pine"), Tectona grandis ("teak"), Acacia decurrens, and Artocarpus heterophyllus ("jak"). Three of these are locally indigenous forest trees, three are exotic forest plantation species, one is a shade tree, and one is very commonly grown in home gardens

\section{Experimental layout}

Fig. I shows the structure of the experimental layout. The apparatus is about $6 \mathrm{~m}$ in height. Commercialy available drip applicators and sprayer nozzles, arranged in a grid, were used to simulate rain. ilhe nozzles giving a coarse rain were assembled in the middle and those giving a fine spray were fixed to the four corners of the grid. The tree branches were attached to the weighing balance in such a way that they hung about $1.5 \mathrm{~m}$ above the ground. The collecting funnel has an area of one square metre.

\section{Experimental method}

A branch from one species, representing a canopy area of about $1 \mathrm{~m}^{2}$. was hung on nylon thread. oriented in the same way as the canopy faces natural rain. The sample was then connected to the electrical balance, and the initial weight recorded.

The shutter was closed above the sample, and spraying was started at a constant rate. The flow rate was measured. then the shutter was opened. The increase in weight of the branch was recorded at $10 \mathrm{~s}$ intervals. The drip, comprising both primary drops from the simulator and sccondary drops from the sample, was collected from the funnel at $60 \mathrm{~s}$ intervals. The spraying was continued tiii the sample indicated a constant weight, and then the shutter was closed. Weight recording continued until there was no more drip. Then the sample was removed and placed in mild sunlight to dry, ensuring that it did not wilt. At each trial the application rates were maintained at $7.4 \mathrm{ml} / \mathrm{s}$ for the fine spray $(F), 5.3 \mathrm{ml} / \mathrm{s}$ for the coarse spray (C), and $11.7 \mathrm{ml} / \mathrm{s}$ for the drip (D). Fine and coarse sprays were obtained by using the sprayer nozzle, while a drip was obtained by using the drip applicators. Constant pressure 
was maintained for each nu by having a constant head in the tank. The procedure was applied twice for each species and application, making $2 \times 8 \times 3=48$ runs in all

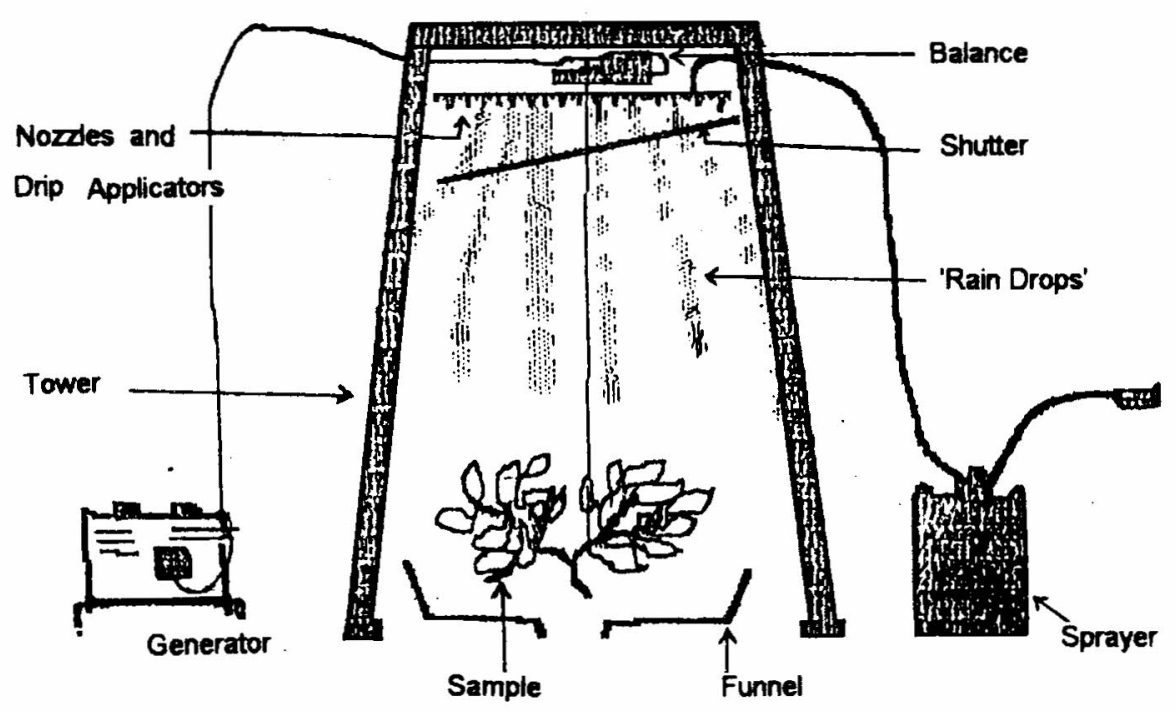

Figure 1: Structure of the experimental layout

\section{Results and discussion}

Figures 2-9 show the wetting patterns of each species. Irrespective of the drop size and the species, the wetting pattern has a characteristic shape in which wetting increases at a decreasing rate until the maximum canopy storage $(\mathrm{Cmx})$ is reached. The sudden drop in each graph indicates the point at which the spraying was stopped. At this point, the continuing rise in sample weight was negligible and the rate at which water was being collected by the funnel was constant. The end of each graph line indicates the point at which all the drainage ceased, when the amount stored is equal to the ultimate canopy storage (CS).

From these experiments, it is apparent that the rate of wetting was fastest for most of the species when the drops were smallest. This effect may be due to the low kinetic energy of small drops, which allows them to adhere quickly to the plant surface, compared with larger drops. For the smaller drops $\mathrm{Cmx}$ was reached within 200-500 $\mathrm{s}$ of the simulator being started, while it took $300-600 \mathrm{~s}$ for the larger drops. For most species drainage had virtually ceased within 300-500 s of the simulator being switched off. 


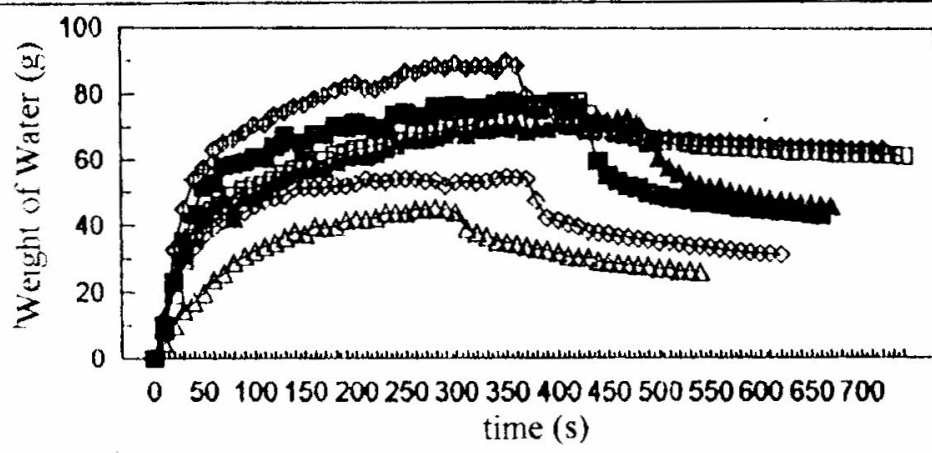

Fig 2 Wetting pattern for Eucalyptus

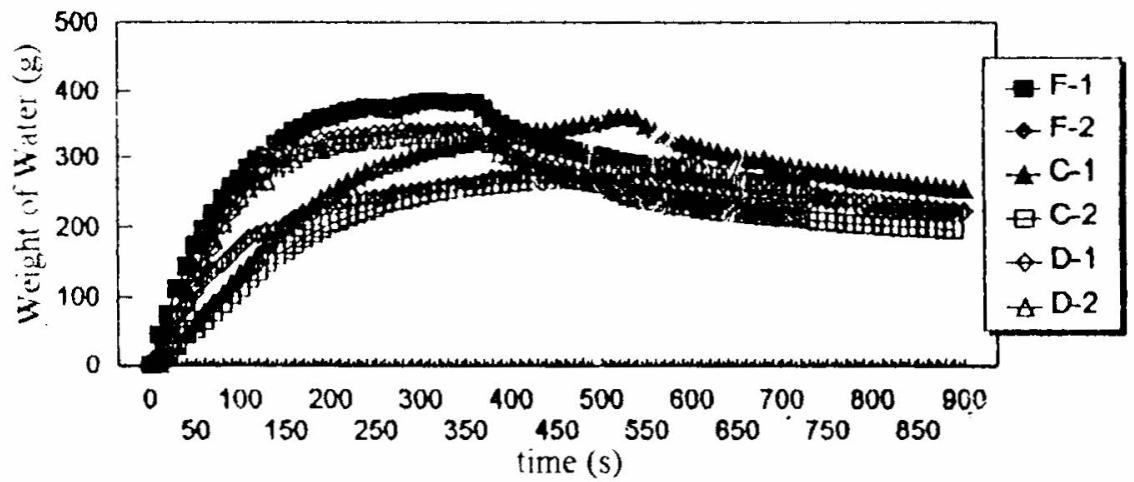

Fig. 3 Wetting pattern for Accasia

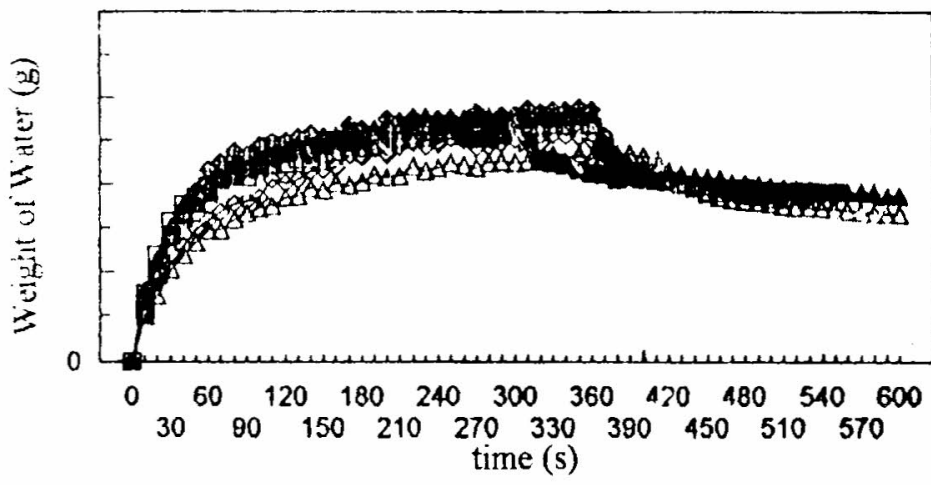

Figures $2,3,4$

F-1, F- 2 Fine C-1, C- 2 Coarse D-1, D- 2 Drip

Fig.4 Wetting pattern for Jak 


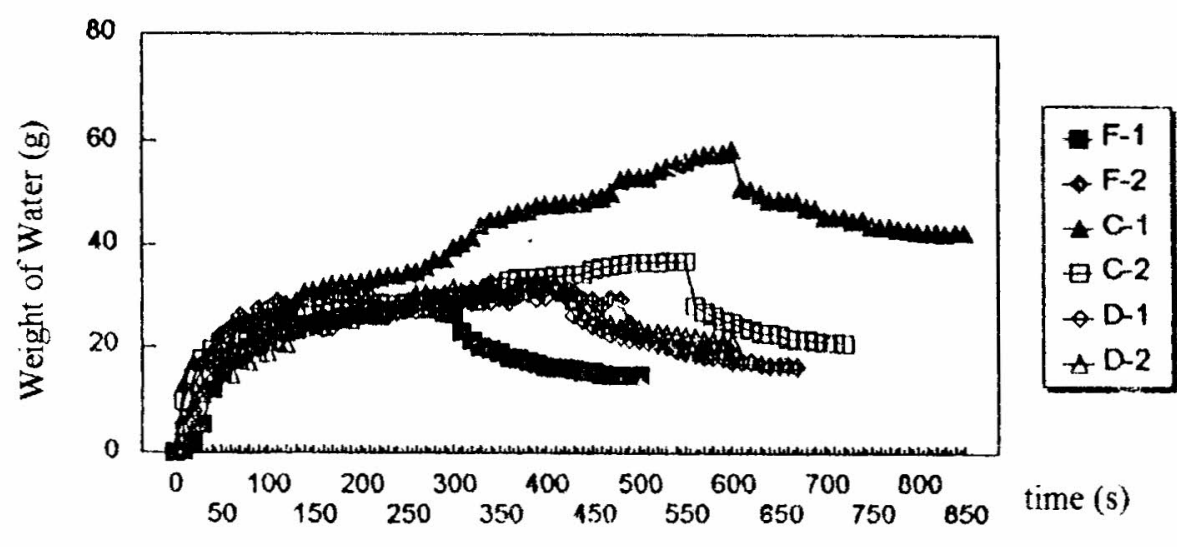

F-1, F- 2 Fine C-1, C- 2 Coarse D-1, D- 2 Drip

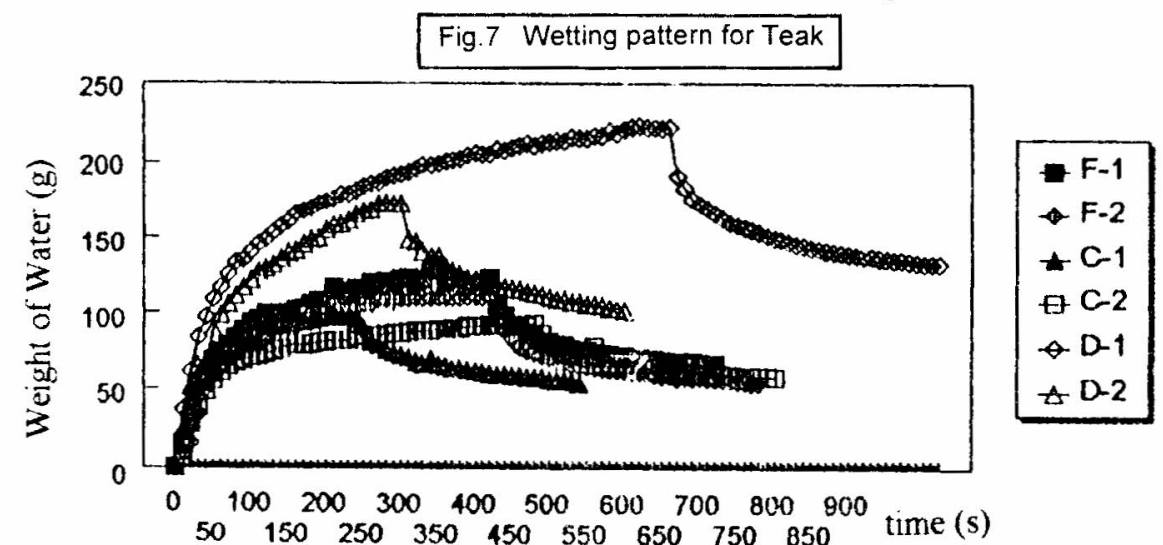

Fig.6 Wetting pattern for Syzygium

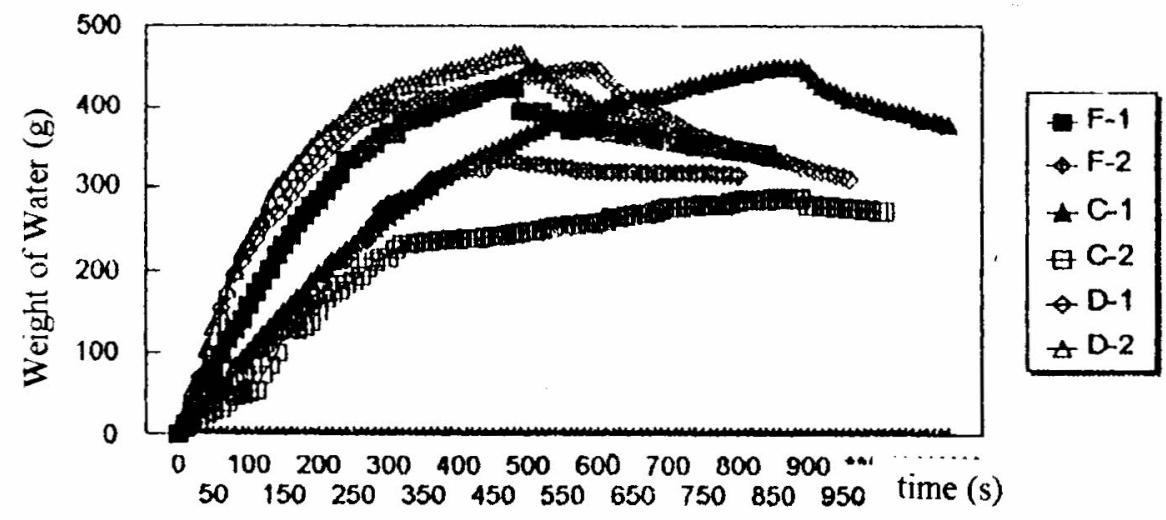

Fig.5 .Wetting pattern for Rhododendron

Figures: 5,6,7

\section{6}



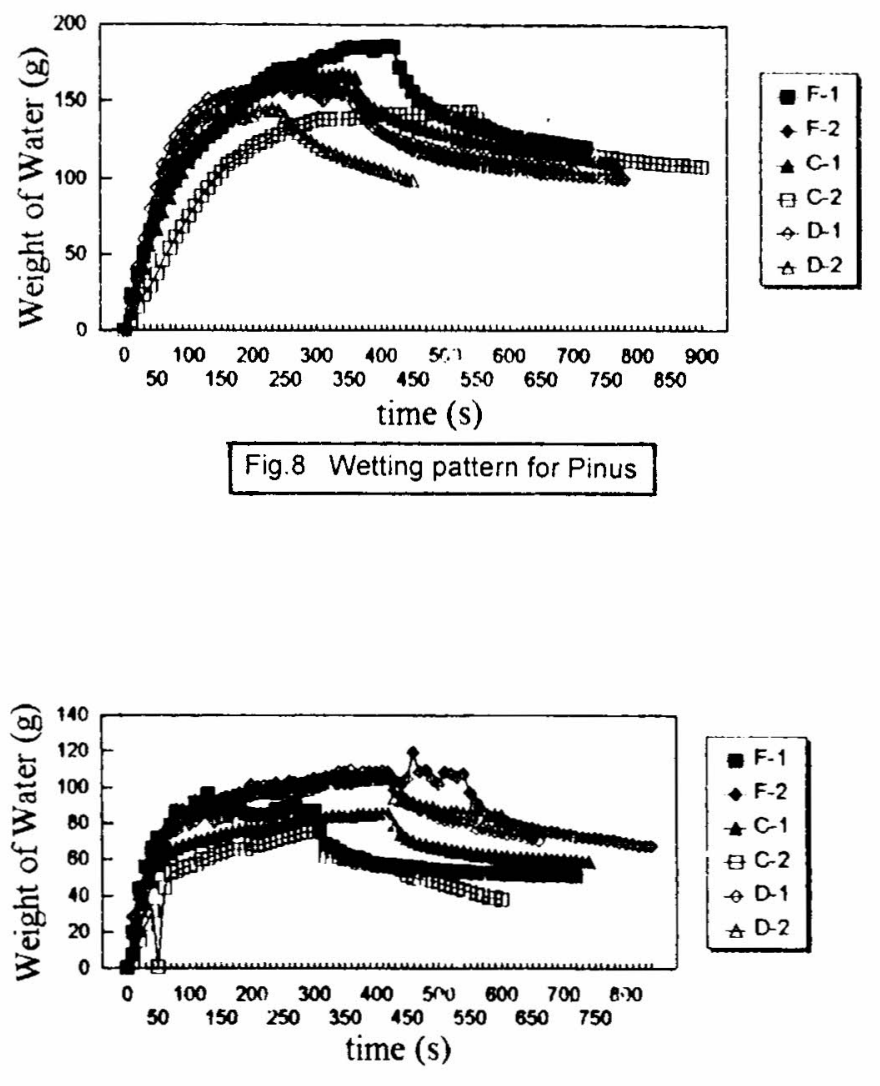

F-1, F- 2 Fine C-1,C- 2 Coarse D- 1, D- 2 Drip

Fig. 9 Wetting pattern for Hedyotis

Figures: 8,9 
Maximum canopy storage (Cmx)

Table 1 shows the $\mathrm{Cmx}$ values for the eight species and three drop sizes for the two replications.

Table 1: Maximum canopy storage ( $\mathrm{Cmx}$ ) for different species and drop sizes (replications $r 1$ and $r 2$ )

\begin{tabular}{cccccc}
\hline Treatment & $\mathbf{r 1}$ & $\mathbf{r 2}$ & Treatment & r1 & r2 \\
\hline A-F & 384.0 & 291.4 & P-F & 185.7 & 161 \\
A-C & 361.0 & 269.2 & P-C & 167.7 & 143.2 \\
A-D & 341.1 & 339.2 & P-D & 159.9 & 144.7 \\
& & & & & \\
E-F & 78.3 & 89.9 & R-F & 128.3 & 110.9 \\
E-C & 72.9 & 77.7 & R-C & 97.2 & 92.9 \\
E-D & 54.8 & 45.1 & R-D & 223.4 & 173.2 \\
J-F & 52.4 & 57.9 & S-F & 424.6 & 331.7 \\
J-C & 56.3 & 53.8 & S-C & 451.4 & 288.4 \\
J-D & 51.6 & 47.7 & S-D & 448.4 & 400.5 \\
& & & & & \\
H-F & 90.5 & 109.3 & T-F & 28.2 & 32.5 \\
H-C & 85.5 & 74.9 & T-C & 58.2 & 36.9 \\
H-D & 109.2 & 105.8 & T-D & 30.6 & 33.4 \\
& & & & & \\
\hline A & & & & & \\
\hline
\end{tabular}

Syzygium, $\mathrm{T}=$ Teak; and $\mathrm{F}=$ Fine, $\mathrm{C}=$ Coarse, $\mathrm{D}=\mathrm{Drip}$.

To examine the significance of species (s). drop size (d) and their interaction ( $\times$ d) on the Cmx. a factorial analysis was carried out for the results given in An analysis of variance (ANOVA) was made, based on the Complete Randomized Design (CRD). The results are given in Table 2.

Table 2 : ANOVA-CRD for Cmax

\begin{tabular}{|c|c|c|c|c|}
\hline Source & d.f & sums of squares & $\mathrm{ms}$ & Fcal \\
\hline Treatment & & 750083.73 & & \\
\hline - species (s) & 7 & 731257.51 & 104465.35 & 83.51 \\
\hline - drop size(d) & 2 & 3231.26 & 1615.61 & 1.29 \\
\hline$-S \times d$ & 14 & 15594.9 & 1113.9 & 0.89 \\
\hline Residual & 24 & 30021.4 & 1250.9 & \\
\hline Total & 47 & 780105.2 & & \\
\hline Correction factor & $=1219983.8$ & & & \\
\hline
\end{tabular}


As the $F$ table values for species, drop size, and interactions were $3.49,5.61$ and 2.90 respectively, at the $1 \%$ significance level, only the species, and not the drop size, is significant in determining Cmx. According to Table 1. Cmx is highest for denser canopies with small leaves, cg. Syzygium, pine, etc, and lowest for the large-leaved species such as teak and jak.

\section{Interception loss}

With time part of the water stored in the canopy drips down, while the rest is evaporated back into the atmosphere. The weight of water corresponding to the end point of each graph, given in Figures 2-9, indicates the ultimate canopy storage (CS), most of which will evaporated, and which is, therefore, important in determining the water lost to the soil. Table 3 shows the CS values given by the different tree species for three different drop sizes for the two replications.

Table 3 : Interception loss (g) by different tree species for three drop sizes

\begin{tabular}{ccccccc}
\hline Treatment & $\mathbf{r 1}$ & $\mathbf{r 2}$ & \multicolumn{1}{c}{ Treatment } & $\mathbf{r 1}$ & $\mathbf{r 2}$ & \\
\hline & & & & & & \\
AF & 255.3 & 216.3 & PF & 119.9 & 99.3 \\
AC & 247.1 & 196.4 & PC & 110.6 & 108.6 \\
AD & 216.9 & 217.0 & PD & 105.6 & 98.4 \\
& & & & & \\
EF & 43.0 & 63.3 & RF & 67.2 & 54.6 \\
EC & 45.5 & 61.0 & RC & 54.6 & 58.3 \\
ED & 31.2 & 25.7 & RD & 132.2 & 101.5 \\
& & & & & \\
JF & 38.0 & 37.1 & SF & 310.4 & 315.0 \\
JC & 37.4 & 36.3 & SC & 351.6 & 273.0 \\
JD & 38.0 & 33.0 & SD & 309.5 & 337.0 \\
& & & & & 16.7 \\
HF & 50.8 & 67.3 & TF & 14.8 & 20.7 \\
HC & 58.9 & 38.3 & TC & 42.5 & 21.3 \\
HD & 70.6 & 84.3 & TD & 19.2 & \\
\hline
\end{tabular}

$\mathrm{A}=$ Acacia, $\mathrm{E}=$ Eucalyptus, $\mathrm{J}=$ Jak, $\mathrm{H}=$ Hedyotis, $\mathrm{P}=$ Pine. $\mathrm{R}=$ Rhododendron, $\mathrm{S}=$ Syzygium, $\mathrm{T}=$ Teak; and $\mathrm{F}=$ Fine, $\mathrm{C}=$ Coarse $\mathrm{D}=$ Drip.

To examine the significance of species (s), drop size (d) and their interaction (s $\times d$ ) on the interception loss, as represented by the ultimate canopy storage (CS), a two-factor factorial analysis (ANOVA) was carried out for the experimental results given in Table 3 . The results are given in Table 4 . 
Table $4:$ ANOVA-CRD for interception loss

\begin{tabular}{lcccc}
\hline Source & d.f & sums of squares & ms & Fcal \\
\hline Treatment & \multicolumn{5}{c}{} & \\
- species (s) & 7 & 464682.1 & \\
- drop size (d) & 2 & 335.9 & 65370.3 & 213.2 \\
- s $\times$ d & 14 & 6753.8 & 482.4 & 1.57 \\
Residual & 24 & 7358.9 & 306.6 & \\
Total & 47 & 472041 & & \\
\hline & & &
\end{tabular}

As the $F$ table values for species, drop size, and interactions were 3.49. 5.61 and 2.90) respectively, at the $1 \%$ significance level, only the species, and not the drop size, is significant in determining $\mathrm{Cmx}$.

Table 5 : Leaf area and LAI for the sample used ${ }^{*}$

\begin{tabular}{lcc}
\hline Species & $\begin{array}{c}\text { Area of one leaf } \\
\left(\mathbf{c m}^{2}\right)\end{array}$ & LAI \\
\hline Acacia & 27.4 & 1.13 .1 .05 \\
Jak & 61.0 & 0.57 \\
Eucalypus & 25.8 & 0.79 .0 .49 \\
Hedyotis & 79.2 & 0.86 \\
Pine & 0.012 & 0.012 \\
Rhododendron & 80.75 & 2.66 \\
Syzygium & 2.0 & 0.83 \\
Teak & 800 & 0.56 \\
\hline
\end{tabular}

* LAI for the sample tested was estimated by dividing total leaf area by the vertical projected area $\left(1 \mathrm{~m}^{2}\right)$

** indicates the area of a compound leaf.

** indicates the area of a single pine needle.

Putting together the leaf size in Table 5 and the interception loss in Table 4, it is clear that for species with smaller leaves the loss is higher. For species with large leaves, the interception loss is higher for those that have a higher LAI. Taking into account both the leaf area and the LAI, then, it is clear that the loss is greatest when the leaf size is small (eg Syzygium) and least when the leaf size is large with a small LAI (eg.Teak). 


\section{Conclusions}

From this study it can be concluded that:

- Each species shows a characteristic wetting pattern, independent of the canopy characteristics and the raindrop size.

- The species plays a significant role in determining the maximum canopy storage (Cmix). It is high in denser canopies that have small leaves.

- The ultimate canopy storage (CS) - or the interception loss - also depends on the species and not on the size of the raindrops.

The following tentative recommendations are made on the basis of this study. Pine is more suitable for planting on south-western slopes with very high rainfall, so that the negative impact on catchment water yield due to very high interception is minimal. In areas where there is considerably less rainfall, large-leaved species with lower LAI are more suitable since they will intercept less of the rainfall.

\section{References}

Calder, I.R. (1995). Dependence of rainfall interception on drop size 1 - Further development of the two layer stochastic model. Journal of Hydrology 185:363-378.

Hall, R.L., I.R. Calder, E.R.N.Gunawardena, P.T.W.Rosier.(1995). Dependence of rainfall interception on drop size: 2.Implementation and comparative performance of the stochastic model using data from a tropical site in Sri Lanka. Journal of Hydroloy 185:363-407. 